\title{
KOMUNIKASI TRANSENDENTAL DALAM PEMENTASAN TARI SANG HYANG LEGONG KERATON LASEM PADA UPACARA TUMPEK WAYANG DI BANJAR ABIANNANGKA KAJA DENPASAR
}

\author{
I Putu Gede Buda Mardiksa Putra a,1 \\ I Wayan Wastawa a \\ I Gusti Ngurah Pertu Agung a \\ a Universitas Hindu Negeri I Gusti Bagus Sugriwa Denpasar \\ 1 Corresponding Author, email: mardiksaputra@gmail.com (Putra)
}

\section{ARTICLE INFO}

Article history:

Received: 12-07-2021

Revised: 19-08-2021

Accepted: 19-09-2021

Published: 30-09-2021

\section{Keywords:}

Transcendental Communication, Sang Hyang

Legong Keraton at Lasem Palace, Tumpek Wayang, Banjar

Abiannangka Kaja

\section{ABSTRACT}

Dance is one of the arts that is quite easy to find in Bali, because many dances are performed as entertainment and are used in religious ceremonies in Bali. One of the classical dances that is sacred and performed during the tumpek wayang ceremony at Banjar Abiannangka Kaja is the Sang Hyang Legong Dance at the Lasem Keraton. Banjar Abiannangka Kaja believes that the dance performance can bring prosperity and is a way of communicating with Ida Sang Hyang Widhi Wasa, who in this case manifests as Ratu Ayu Alit Mas Suci who resides at the Banjar Temple. The formulation of the problem in this article is (1) the existence of the Sang Hyang Legong dance at the Lasem Keraton at the Tumpek wayang ceremony (2) the form of transcendental communication in the Sang Hyang Legong dance performance at the Lasem Keraton (3) the implications of transcendental communication on people's lives after performing the Sang Hyang Legong dance. Keraton Lasem The theories used to analyze the three problem formulations in this study are (1) Theory of Religion, (2) Theory of Extraordinary Powers and (3) Theory of Symbolic Interaction. This study uses a qualitative method. The results of this study indicate several things, such as: First, this Legong dance performance still survives today because it is believed to expel negative forces and can bring prosperity. Second, there are two forms of transcendental communication in this dance performance, namely the type of verbal communication (Pedudusan Sang Hyang Dedari singing, sesontengan and mantra) and the type of nonverbal communication (banten and dance movements). In this type of verbal and non-verbal communication, there is transcendental communication between humans and God from every meaning contained in songs, mantras, offerings and movements, both expressed and implied. Third, the implications for people's lives such as in religious life, social life, culture and the teachings of Tri Hita Karana.

\section{PENDAHULUAN}

Manusia adalah makhluk yang diciptakan dengan kelebihan yaitu dengan pikiran serta caranya untuk mengendalikan diri. Manusia disebut sebagai makhluk sosial karena manusia tidak dapat hidup sendiri dan selalu 
membutuhkan orang lain dalam memenuhi kebutuhannya, salah satunya dengan cara interaksi sosial (communication hunger) (Suranto, 2011:44). Komunikasi memegang peranan penting dalam interaksi sosial manusia. Komunikasi adalah ketika seseorang menyampaikan sesuatu kepada orang lain baik itu pemikirannya atau informasi yang lainnya bisa secara langsung maupun tidak langsung. Selain berkomunikasi secara horizontal yaitu dengan individu atau kelompok tertentu manusia juga perlu berkomunikasi secara vertikal yaitu dengan Tuhan. Dalam ilmu komunikasi, cara berkomunikasi manusia dengan Tuhan adalah dengan menggunakan komunikasi transendental. Komunikasi transendental adalah komunikasi yang masih sedikit di bahas cukup luas, hanya sebatas cara manusia yang berkomunikasi dengan Tuhan, untuk itulah komunikasi transendental masuk ke dalam bidang agama. Meskipun sifatnya susah untuk diamati justru komunikasi transendental sangan berperan penting bagi manusia, bukan hanya untuk di dunia namun menentukan akhirat (Mulyana, 2001:49).

Bagi Umat Hindu khususnya di Bali, penerapan komunikasi transendental adalah ketika memusatkan pikiran kepada Ida Sang Hyang Widhi Wasa dengan segala manifestasinya. Diantaranya yang bisa dilihat adalah ketika bersembahyang, meditasi, yoga dan upacara keagamaan. Upacara adalah salah satu cara komunikasi transendental yang paling kompleks karena dalam upacara terdapat beberapa media komunikasi yang digunakan, diantaranya adalah kesenian. Kesenian di Bali jika dilihat dari perspektif Hindu mempunyai kedudukan yang sangat mendasar dengan konsep Satyam Sivam Sundaram (kebenaran, kesucian dan keindahan), karena kehidupan religi agama Hindu tidak bisa dilepaskan dari kesenian dan seni adalah simbol penjabaran Veda (Yudabakti dan Watra, 2007:32).
Salah satu kesenian yang dipakai atau lebih tepatnya dipentaskan ketika upacara agama di Bali adalah Tari Sang Hyang Legong keraton Lasem, tari ini termasuk masuk kedalam jenis tari sanghyang dedari yang di pentaskan setiap Tumpek Wayang. Tari legong ini ditarikan oleh tiga orang remaja perempuan yang belum mengalami haid, yang dipilih berdasarkan atas petujuk niskala yang dalam hal ini berkaitan dengan komunikasi transendental. Pementasan tari legong ini dilakukan di Banjar Abiannangka Kaja serta secara rutin dipentaskan ketika upacara tumpek wayang yang notabene dipercaya sebagai simbol keharmonisan manusia dengan kesenian, justru tari legong ini tidak dipentaskan ketika tumpek wariga yang merupakan odalan yang tujukan kepada Bagawan Penyarikan yaitu odalan di banjar pada umumnya. Fenomena ini menarik untuk dikaji, terutama pada aturan-aturan penari yang belum datang bulan (haid), yang kedua dari perkembangannya tari legong muncul sangat jauh belakangan. Selanjutnya yang menarik untuk dikaji adalah tentang eksistensi tari legong ini sampai sekarang, komunikasi transendental yang terdapat dalam tari ini serta implikasi terhadap kehidupan masyarakat

\section{METODE PENELITIAN}

Jenis dan pendekatan dalam penelitian ini mempergunakan metode kualitatif. Lokasi penelitian bertempat di Banjar Abiannangka Kaja Desa Kesiman Petilan Kecamatan Denpasar Timur Kota Denpasar. Penentuan informan mempergunakan teknis purposive sampling. Jenis dan sumber data yang dipergunakan adalah kualitatif dan sumber data yang dipergunakan berupa data primer dan data sekunder. Instrumen penelitian mempergunakan Camera Digital dan Tape Recorder, inti instrumen peneliti adalah peneliti itu sendiri. Teknik pengumpulan data yang dipergunakan seperti : observasi, wawancara, studi kepustakaan. 
Teknik analisis data dilakukan dengan beberapa tahapan seperti : reduksi, penyajian data, dan penarikan kesimpulan. Teknik penyajian hasil penelitian dilakukan dengan metode deskriptif.

\section{HASIL DAN PEMBAHASAN}

\section{Eksistensi pementasan tari Sang Hyang} Legong Keraton Lasem pada upacara Tumpek Wayang

Menurut Jazuli (2016: 7) eksistensi tari dalam suatu masyarakat beserta kebudayaan yang melingkupinya muncul melalui proses ruang dan waktu, tidak muncul dan tidak hadir secara tiba-tiba. Ruang biasanya terkait dengan peristiwa dan kepentingan (performa) serta sistem nilai, sedangkan waktu terkait dengan proses produksinya (penciptaan). Misalnya sebuah tari diciptakan untuk kepentingan identitas suatu daerah, maka performanya akan mencerminkan visi dan misi serta sistem religi. Religi atau agama pada dasarnya merupakan kepercayaan terhadap adanya kekuatan gaib, luar biasa atau supernatural yang berpengaruh terhadap kehidupan individu dan masyarakat, bahkan terhadap gejala gejala alam. Kepercayaan itu menimbulkan perilaku tertentu dari individu ataupun masyarakat yang mempercayainya seperti berdoa, memuja dan lainnya, serta menimbulkan sikap mental tertentu, seperti takut, pasrah, optimis dan lain sebagainya. Sama hal nya dengan Tari Sang Hyang Legong Keraton Lasem yang disakralkan dan dipentaskan ketika hari tertentu serta dipercayai oleh masyarakat Banjar Abiannangka Kaja Desa Kesiman Petilan yang keberadaannya masih sampai sekarang dengan sejarah, proses pementasan serta kepercayaan masyarakat sekitar dengan tarian ini.

Eksistensi pementasan Tari Sang Hyang Legong Keraton Lasem telah ditunjukkan dengan adanya pementasan-pementasan yang dilakukan sampai tahun 2021. Ini membuktikan bahwa pementasan Tari Sang Hyang Legong Keraton
Lasem masih eksis dan telah diakui oleh masyarakat, serta adanya kerjasama antara pelaku seni di Banjar Abiannangka Kaja dengan salah satu dosen Isi Denpasar. Seperti yang dikatakan oleh I Made Darma yaitu salah satu tokoh masyarakat di Banjar Abiannangka Kaja mengatakan bahwa Tari Sang Hyang Legong Keraton Lasem adalah salah satu kesenian tradisional yang dimiliki oleh Banjar Abiannangka Kaja yang harus dilestarikan keberadaannya. Salah satu upaya untuk menjaga eksistensi tari ini adalah dengan melakukan pembinaan tari legong dengan pelatih tari $\mathrm{Ni}$ Nyoman Manik Suryani. SST., M.Si yang merupakan dosen seni tari di Isi Denpasar. Tidak hanya tariannya saja, penabuh juga dilakukan pembinaan dari sejak dini agar adanya regenerasi penabuh nantinya, pembiaan tabuh ini dibuktikan dengan adanya Sekha Tabuh Sekar Kumara.

\section{Bentuk komunikasi transendental dalam pementasan Tari Sanghyang Legong Keraton Lasem pada upacara tumpek wayang}

Komunikasi memiliki beberapa bentuk yang sering digunakan dalam kehidupan seharihari termasuk juga komunikasi transendental. Bentuk-bentuk komunikasi transendental tertuang dalam aktivitas keagamaan umat yang berkomunikasi dengan Tuhan, bentuk-bentuk komunikasi transendental yang paling lumrah dilakukan antara lain adalah bentuk komunikasi verbal dan nonverbal. Komunikasi verbal adalah bentuk komunikasi yang paling sering dilakukan dalam setiap interaksi sosial. Komunikasi verbal dilakukan secara lisan atapun bisa dengan tertulis. Sedangkan komunikasi nonverbal adalah setiap bentuk prilaku manusia yang langsung dapat diamati oleh orang lain dan yang mengandung informasi tertentu tentang pengirim atau pelakunya atau bisa juga menggunakan simbol-simbol tertentu. 
Komunikasi verbal yang terdapat pada pementasan Tari Sang hyang Legong Keraton Lasem adalah dengan nyanyian pedudusan sang hyang dedari. Nyanyian tersebut menggunakan bahasa alus madia. Nyanyian tersebut dinyanyikan oleh krama istri atau oleh ibu-ibu warga banjar. Nyayian ini terdiri dari 9 bait yang dinyanyikan berulang-ulang sampai para penari tidak sadarkan diri, adapun nyanyiannya adalah sebagai berikut:

1. Kebiar-kebiur agending me, rebere ring parawe, ya sampan nudus ya ya gending mare baija raga ya dodol tamblang, ya e dodol, lan singgih kasele, ya kuncantel ontalin ya kutungkul ya ya mabelayar ya malayar ya ngelod nganginan, ya manuju taman magendra, ya tamane ya ya madaging sekar, sekar anggrek, ya anggrek gu, lan anggrek geringsing, ya tiga kancu ya ya pala lepe, ya parigi ya ya batur mejajar.

2. kebiar-kebiur agending me, mare bere ring perawa ya ya sampan-sampan nudus, ya ya gending-gending mare baija raga dodol tamblang dodol tamblang ya e dodol lan singgih kasele, ya ya rearekocantel ontalinontalin kamene ya ya katujune mabelayarmabelayar, adi melayar, ya ngelod angaja kaninan ya ya ayu dedari, ya ya ne metanggun jero ya ya tamane medaging sekar, sekar emas sadi-sanding ine pudak anggrek geringsing, ya ya tiga kancu ya ya manasele sempol ya ya kedapane pala kelayu lepe

3. Kembang jenar ya mangundangan dedari agung, ya ya dane ya dane becik, becik-becik undang, ya ya rangsuk praba nunjung biru, nunjung beru, ya marangsukan menganggoanggo ya ya menya ya ya lecat mi be rangga gana, rangga gana ya mengilukan ngelod ngaaja kanginan ya ya yu ayu dedari ne metanggun jero ya ya tamane me daging sekar, sekar emas sesandingina pudak anggrek geringsing, ya ya tiga ya tiga kancu manasele sempol, ya ya kedepane kembang ke nagasari

4. Kembang jenar ya mangundangan dedari agung, dane ya dane becik, becik-becik undang, ya rangsuk-rangsuk praba nunjung biru, nunjung beru, ya marangsukan menganggo-anggo,menyalukin baju kemaskemas, ya lecat-lecet miba rangga gana, rangga gana ya mengilukan ngelod ngaaja kanginan dedari metanggun jero, ya tamantama ne medaging sekar, sekar emas sesandingine pudak anggrek geringsing, kancu mana sele sempol ya kedep kedapane kembang nagasari.

5. Yu dedari, ye dane lunga ngendan-ngendon memendet ya memendete, ya mengilehin ya sanggah ra gung, ya mebaktine mengatur aturan canag, ya dikurine ya kurine gadung kasturi, ya ya selaginban, lan soka ngasti, ya somanase ya somanasegala kastangi, ya ya yu dedari ya yu dedari mengempol sekar, ya sekar sandat ya silayu-layune miyik, ya ya miyik ngalub, ya miyik ngalub maimpungan.

6. Ya selaginban ya selaginban tunjung biru, ya ya tunjung tutur ya tunjung tutur tangguli gending. Ye selaginban ya selaginban sokanata, ya ya sokanata, ya sokanata gadung-gadung melati. Ya sekar sempol mengadanin, ya ya sekar jempiringe ya rejasene lan siulan. Ya sasak gunung, ya serunine lan kewanta, ya ya sekar danigarane ya tigarane nagasari.

7. Ya sungengene ya sungengene katrangan menuh, ya tanjung oja ya tanjung oja menugambir, ya jumpakane ya jumpakane ne memutih, ya ya ler mewane ya lergulane mesari ratna. Ya sekar rame ya sekar rame balih gambuh, ya ya gambuh nese ya gambuh ne saking sowarga. Ya nemamutri ya nemamutri sang supraba, ya ya lawatinban ya lawatinban bulan purnama, ya kenyahkenyah manguranyah, ya ya ayu made ya hiluh tama manampa canag, ya tangan dane 
ya tangan dane lemet melengkung, ya ya canag dane ya canag dane dewi suci.

8. Sekar jepun ya angrek tane manori putih, teleng petak tunjung biru ya dedari mekarya tirta, tirta ene masibuk mase toye pemastu saking sowarga dong siratin ragan idewa, wus masirat dong ketisine juru kidunge mantuk maring indraloka ya waluya dadi manusa.

9. Utur-utur ya dudupana, ya dedari idewa munggah, ya saking sawang, idewa lesu, ke mercepada idewa mantuk, ya mangilehin ya titiang serak, ya mangambelin ya parekane, ya sami rawuh, ya pangwine, mapontang emas ya jumpanene ya mapurada ya pajeng kuning, ya makembarin ya jalan meru, ya tumpang solas ya jalan dedari memarek ya gending-gending

Selanjutnya komunikasi verbal yang terdapat dalam pementasan tari Sang Hyang Legong Keraton Lasem dengan menggunakan mantra dan sesontengan. Sesontengan adalah doa yang berisi permohonan serta permintaan yang bernuansa magis yang mempergunakan bahasa sehari-hari. Penggunaan bahasa disini adalah bahasa sehari-hari yang tentu jika berbeda tempat maka akan berbeda bahasa juga, misalnya sesontengan orang Bali maka akan menggunakan bahasa Bali baik bahasa Bali halus atau basaha Bali serhari-hari atau sering disebut bahasa kepara, begitu pula sesontengan orang jawa maka akan menggunakan bahasa jawa. Di Bali sendiri karena mendapat pengaruh dari kerajaan majapahit, seringkali sesontengan di Bali menggunakan bahasa jawa kuno atau bahasa kawi. Dalam upacara Tumpet Wayang di Desa Kesiman Petilan khususnya di Banjar Abiannangka Kaja, penggunaan sesontengan serta mantra selalu beriringan. Sesontengan dipergunakan sebagai sebuah permohonan kepada sesuhunan dan mantra dipergunakan sebagai penegasan dari sesontengan tersebut, adapun sesontengan yang digunakan dalam pementasan tari legong ini diucapkan oleh pemangku seperti berikut:

Om sugra tabek pakulun sasuhunan Ratu Ayu Alit Mas Maketel, kaiiring antuk dedariira wenten atur manusan paduka bhatara sarinin tasik cemeng, kawas daun, pasucian, isin pasawahan agung, kareka antuk manusa ring maya pada, kalebur ring jaba tengah, natar palinggih paduka bhatara maruntutan segehan manca warna, selem putih mangda sampun ngoda ring sedahan mapakeling. Om sidhi rastu ya namah swaha.

Artinya:

Oh Hyang Widhi, Tuhan yang bermanisfestasi sebagai Ratu Ayu Alit Mas Maketel, yang diiringi oleh Dedari. Hamba menghaturkan persembahan berupa tasik cemeng, kawasan daun, pesucian serta hasil pertanian yang dibuat oleh hamba. Hamba haturkan di jaba tengah, didepan persemayamanMu hamba menghaturkan segehan panca warna, segehan poleng dan di sedahan hamba telah menghayatkan. Semoga damailah keadaannya.

Komunikasi nonverbal juga terdapat dalam pementasan Tari Sang hyang Legong Keraton Lasem yang dituangkan dalam bentuk gerakan tari dan penggunaan banten. Wiana (2001: 17) menyatakan banten dalam Lontar Yadnya Prakerti adalah bahasa agama, adapun kutipanya lontar tersebut adalah:

Sehananing "banten" pinaka raganta twi, pinaka warna rupaning Ida Bhatara, pinaka Andha Bhuwana.

Artinya:

Semua Bebanten adalah lambang dirimu sendiri,

lambang Kemaha- kuasaan Tuhan dan lambang isi alam semesta. 
Melalui sarana banten umat Hindu menyampaikan rasa terima kasih kepada Ida Sang Hyang Widhi Wasa atau Tuhan Yang Maha Esa. Banten juga dipergunakan pada upacara Tumpek Wayang di Desa Kesiman Petilan, khususnya di Banjar Abiannangka Kaja. Terdapat berbagai jenis banten yang juga memiliki makna serta komponen-komponen di dalamnya. Adapun beberapa banten yang dipergunakan seperti; daksina, banten peras, blabaran, banten suci, banten semayang dan penyambleh. Semua banten tersebut adalah satu kesatuan dengan pementasan Tari Sang Hyang Legong Keraton Lasem. Setiap banten mempunyai arti serta tujuan sebagai bentuk terima kasih, permohonan maaf serta dipercaya mendatangkan kesejahteraan bagi seluruh warga banjar.

Selanjutnya adalah komunikasi nonverbal dengan menggunakan gerakan tari. Tari merupakan salah satu bentuk ekspresi jiwa yang dituangkan dalam bentuk gerak. Tari adalah salah satu bagian dari kesenian yang sejak zaman dulu dipakasi sebagai sarana hiburan bahkan sebagai sarana penunjang upacara adat atau agama. Gerakan dalam tari dibangun berdasarkan ritmis yang indah serta disatukan oleh begitu banyak nilai kultur dari kelompok individu yang mendukungnya (Bandem, 1997: 7).

Dalam pementasannya, tari Sang Hyang Legong Keraton Lasem terdiri dari beberapa bagian seperti pengawit, pengawak, pengecet, pengetog dan pekaad. Manik Suryani adalah selaku penari serta pelatih tari Sang Hyang Legong Keraton Lasem di Banjar Abiannangka kaja, menjelaskan masing-masing bagian dalam pementasan tari tersebut memiliki cirinya masing-masing. Pengawit adalah pembukaan tari, pengawit sendiri secara umum dipakai oleh semua tema Tari Legong Keraton termasuk Tari Sang Hyang Legong Keraton Lasem yang akan diiringi dengan gending pengawit. Selanjutnya beliau menjelaskan pengawak, adalah bagian pokok dalam pementasan tari Sang Hyang Legong Keraton Lasem, bagian pengawak diiringi oleh gending pengawak yang dipadukan dengan juru tandak yaitu dalang yang membawakan alur cerita Prabu Lasem. Pengecet adalah rangkaian dari pengawak yang dipadukan dengan gending penyecet. Bagian ke empat adalah bagian pengetog, yaitu pesiat atau pertarungan dimana condong berubah menjadi burung garuda yang dikalahkan oleh legong yang berubah menjadi patih. Dalam pementasan di Banjar Abiannangka Kaja ketika bagian pengetog inilah Ida Sesuunan Ratu Ayu Alit medal, bagian ini diiringi dengan gending pengetog. Bagian terakhir adalah pekaad yang diiringi dengan gending pekaad.

Dalam tari Bali ragam gerak disetiap tarian yang bawakan terdiri dari dua jenis gerakan antara lain adalah gerakan murni dan gerakan maknawi. Gerakan murni adalah gerakan yang diambil dari lingkungan sekitar seperti aktivitas binatang dan tumbuhan serta kegiatan seharihari manusia. Kedua adalah gerakan maknawi adalah gerakan yang memiliki makna serta arti khusus yang mengandung pesan didalamnya. Contoh gerakan murni yang terdapat dalam Tari Sang Hyang Legong Keraton Lasem adalah; ngeliput, gulu wangsul, ngenjet, ngubit, ngelo, ngencet, tanjek mentang, agem serta yang lainnya. Selanjutnya contoh gerakan maknawi adalah; nyalud yaitu gerakan tangan yang seolah-olah mengambil sesuatu, ulap-ulap yaitu kerakan seolah melihat sesuatu dikejauhan, nuding yaitu gerakan jari tangan seperti menunjuk sesuatu.

$S$ ebuah gerakan yang dikemas dalam sebuah seni tari akan dapat menyampaikan sebuah pesan dalam hal ini adalah pesan nonverbal. Melalui gerakan tari yang indah serta dipadukan dengan irama gamelan yang merdu, sebuah pesan dan maksa akan tersampaikan dengam baik kepada individu serta kelompok 
masyarakat yang mendukungnya. Melalui pementasan Tari Sang Hyang Legong Keraton Lasem Masyarakat diajarkan mengharmoniskan sifat baik dan buruk dalam diri.

\section{Implikasi Komunikasi Transendental} terhadap Kehidupan Masyarakat setelah Melaksanakan Pementasan Tari Sang Hyang Legong Keraton Lasem pada Upacara Tumpek Wayang

Secara umum implikasi bisa diartikan sebagai keterlibatan, yang berpengaruh atau terlibat namun tidak jelas dinyatakan atau bisa disebut tersirat. Implikasi jika dilihat dari sudut pandang agama khususnya agama Hindu adalah keterlibatan sebuah ajaran kepercayaan yang memberi pengaruh atau efek pada kehidupan umatnya. Pementasan Tari Sang Hyang Legong Keraton Lasem pada upacara Tumpek Wayang di Banjar Abiannangka Kaja memiliki sistem serta struktur yang masih dipertahankan sampai saat ini. Pementasan Tari Sang Hyang Legong Keraton Lasem ini memberikan pengaruh atau dampak yang dirasakan langsung ataupun tidak langsung yang terimplikasi dalam kehidupan masyarakat. Implikasi tersebut adalah implikasi komunikasi transendental yang meliputi implikasi pada kehidupan religius, implikasi pada kehidupan sosial, implikasi terhadap budaya dan implikasi terhadap ajaran tri hita karana.

\section{a. Implikasi Implikasi Komunikasi Transendental pada Kehidupan Religius}

Religius berarti keseluruhan nilai yang besifat keagamaan dan yang berkenaan dengan kepercayaan agama (Roibin, 2009: 75). Dapat disederhanakan religius adalah sikap dan perilaku yang patuh dalam melaksanakan ajaran agama yang dianutnya, menjaga hubungan baik dengan agama lain serta berhubungan harmonis dengan pemeluk agama lainnya. pementasan Tari Sang Hyang Legong Keraton Lasem adalah bentuk kepercayaan warga masyarakat dengan adanya Tuhan. Melalui pementasan tari ini warga masyarakat berkomunikasi dengan Tuhan untuk memohon keselamatan dan kesejahteraan. Hal ini berimplikasi terhadap kehidupan religius warga masyarakat sekitar, terlihat dari tekun dan taatnya krama banjar melaksanakan pementasan tari legong ini serta kepercayaan yang sudang mendarah danging yang dimiliki oleh krama Banjar Abiannangka Kaja terhadap pementasan Tari Sang Hyang Legong Keraton Lasem.

\section{b. Implikasi Komunikasi Transendental pada Kehidupan Sosial}

Sebagai makhluk sosial dan hidup berkelompok dalam kehidupan sehari-hari, tentu tidak luput dari namanya interaksi serta komunikasi. Pementasan Tari Sang Hyang Legong Keraton Lasem sendiri juga tidak lepas dari yang namanya interaksi sosial dan komunikasi. pementasan Tari Sang Hyang Legong Keraton Lasem memupuk rasa persaudaraan antara warga masyarakat di Banjar Abiannangka Kaja. Dengan pementasan tari ini, interaksi sosial antar warga masyarakat terjadi mulai dari persiapan sampai di akhir pementasan nanti. Bertukar pikiran serta informasi ketika persiapan upacara, saling memberikan pengertian tentang berkomunikasi dengan Tuhan ketika melaksanakan persembahyangan adalah salah satu bentuk kehidupan sosial yang terjalin dengan baik di lingkungan Banjar Abiannangka Kaja.

\section{c. Implikasi Komunikasi Transendental terhadap Budaya}

Budaya merupakan hasil cipta, karya dan karsa manusia yang lahir atau terwujud setelah diterima oleh masyarakat atau komunitas tertentu serta dilaksanakan dalam kehidupan sehari hari dengan penuh kesadaran tanpa pemaksaan dan ditransmisikan pada generasi selanjutnya secara bersama (Fathurrohman 
2015: 48). Sama halnya dengan kesenian, budaya juga erat kaitannya dengan agama. Agama Hindu khususnya yang berada di Bali melaksanakan ajaran agama dengan mengikutsertakan budaya di dalamnya, yang mengakibatkan agama dan budaya sulit dipisahkan satu sama lainnya. Melibatkan seni tari dalam sebuah upacara mengakibatkan tari dalam hal ini termasuk budaya akan terjaga keberadaannya.

\section{d. Implikasi Komunikasi Transendental terhadap Ajaran Tri Hita Karana}

Konsep ajaran Hindu bahwa kebahagiaan hanya terwujud jika adanya hubungan yang harmonis antara manusia dengan Tuhan, manusia dengan manusia, dan manusia dengan alam. Ajaran ini disebut Tri Hita Karana atau tiga faktor penyebab terwujudnya kebahagian (Wiana, 2004: 141). Bentuk ajaran tri hita karana di Desa Kesiman Petilan khususnya di Banjar Abiannangka Kaja adalah pelaksanaan upacara tumpek wayang yang didalamnya terdapat pementasan Tari Sang Hyang Legong Keraton Lasem yang berlandaskan atas kerangka dasar agama Hindu yaitu Tattwa, Etika dan Upacara. Dalam pengamalan parhyangan adalah pementasan tari legong ini adalah cara berkomunikasi dengan Tuhan yang sekaligus menjaga hubungan antara manusia dengan Tuhan. dalam pengamalan pawongan terjadi ketika interaksi antar warga yang secara langsung menjaga hubungan antar sesama manusia. Terakhir adalah pengamalan palemahan terjadi ketika melakukan pemeliharaan lingkungan sekitar seperti area banjar serta membersihkan area pura atau yang sering disebut mereresik.

\section{SIMPULAN}

Berdasarkan hasil penelitian, maka dapat ditarik beberapa kesimpulan yaitu eksistensi Tari Sang hyang Legong keraton Lasem bisa terjaga sampai saat ini karena pementasan tari ini dilaksanakan rutin setiap upacara tumpek wayang serta kepercayaan masyarakat dengan pementasan tari legong ini merupakan wujud terima kasih kepada Tuhan. Bentuk komunikasi transendental dalam pementasan tari legong ini ada dua yaitu komunikasi verbal dan nonverbal. Dalam komunikasi verbal menggunakan nyanyian sang hyang dedari, mantra serta sesontengan. Dalam komunikasi nonverbal menggunakan sarana banten dan gerakan tari. Selanjutnya implikasi komunikasi transendental dalam kehidupan masyarakat berupa implikasi pada kehidupan religius ditunjukan dengan meningkatnya sradha bhaktu kepada Ida Sang Hyang Widhi Wasa, implikasi pada kehidupan sosial ditunjukkan dengan terpeliharanya hubungan baik antar warga, implikasi terhadap budaya ditunjukkan dengan terjaganya budaya dalam hal ini tari dan tabuh dan implikasi terhadap ajaran tri hita karana tidunjukkan dengan terjaganya hubungan anatar manusia dengan Tuhan, manusia dengan manusia serta manusia dengan lingkungan sekitar.

\section{DAFTAR PUSTAKA}

Wiana, I Ketut, 2006. Beragama Bukan Hanya di Pura, Denpasar : Yayasan Dharma Naradha

Muhammad Fathurrohman. 2015. “Budaya

Religius dalam Peningkatan Mutu Pendidikan: Tinjauan Teoritik dan Praktik Kontekstualisasi Pendidikan Agama Islam di Sekolah". Yogyakarta: Kalimedia

Roibin. 2009. "Relasi Agama dan Budaya Masyarakat Kontemporer". Malang: UIN Maliki Press.

Bandem, I Made, 1997. Ensiklopedi Musik dan Tari Daerah Bali Denpasar: Proyek Penelitian dan Pencatatan Kebudayaan Daerah Departemen Pendidikan dan Kebudayaan. 
Jazuli, M. 2016. "Peta Dunia Seni Tari". Sukoharjo: CV. Farishma Indonesia.

Yudabakti, I Made dan Watra, I Wayan. 2007. "Filsafat Seni Sakral dalam Kebudayaan Bali". Surabaya: Paramitha.

Deddy Mulyana. 2001. "Ilmu Komunikasi Suatu Pengantar, Cet. XIV". Bandung: PT. Remaja Rosdakarya

Suranto, Aw. 2011. Komunikasi Interpersonal. Yogyakarta : Graha Ilmu 